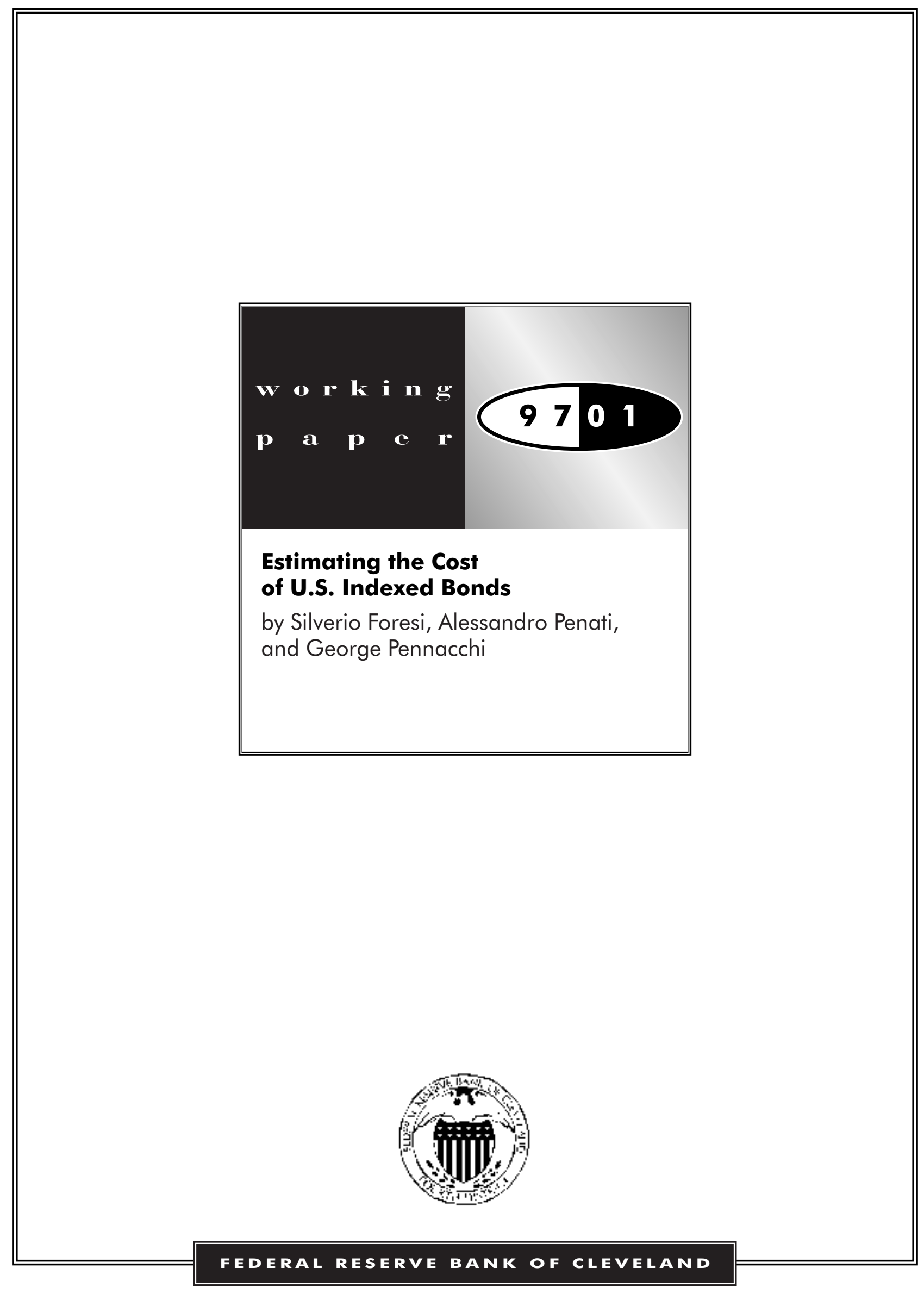




\title{
Estimating the Cost of U.S. Indexed Bonds
}

\author{
Silverio Foresi*
}

Alessandro Penati ${ }^{\dagger}$

George Pennacchi ${ }^{\ddagger}$

Initial Draft: August 4, 1996

This Revision: January 7, 1997

\begin{abstract}
This paper presents an equilibrium bond pricing model driven by two stochastic factors: the real interest rate and the expected rate of inflation. The model's parameters are estimated using a maximum likelihood technique based on a Kalman filter. Data on nominal U.S. Treasury securities and Survey of Professional Forecasters predictions of the GDP deflator are employed to identify the separate effects of real and nominal variables. The market prices of real interest rate risk and inflation risk are estimated, which allows us to construct yield curves for nominal and indexed U.S. Treasury securities. The relative costs of nominal and indexed bonds can then be assessed.
\end{abstract}

We are grateful for the comments of seminar participants at the Federal Reserve Bank of Cleveland.

*Department of Finance, New York University, (212) 998-0358, sforesi@stern.nyu.edu.

$\dagger$ Department of Economics, Bocconi University and University of Sassari, 31-2-8394044, apenati@mbox.vol.it.

${ }^{\ddagger}$ Department of Finance, University of Illinois, (217) 244-0952, gpennacc@uiuc.edu. 


\section{Introduction}

For many years, economists have proposed that the United States government issue bonds having payments indexed to a price level. ${ }^{1}$ Until recently, most government officials had not shared economists' attraction for indexed bonds. However, the current political pressure to reduce Federal budget deficits may have led some government policymakers, including officials at the U.S. Treasury Department, to re-think their view. A likely reason for this change of heart is the current belief that indexed bonds could reduce the Federal government's debt servicing costs.

On May 16, 1996, the U.S. Treasury Department announced plans to begin selling bonds with payments indexed to inflation. In its proposal, the Treasury states that the primary reason for offering these bonds is to reduce the expected interest costs paid by the Federal government and to provide an alternative debt instrument that many investors could find attractive:

Because the Treasury, rather than the investor, would bear the inflation risk on an inflation-protection security, the Department expects that the prices at which it would sell this new type of security would capture some or all of the inflation risk premium charged by investors on conventional Treasury securities. In other words, investors should be willing to pay extra for a security on which the issuer, rather than the investor, bears the risk of higher than expected inflation. Consequently, the expected interest costs to the Treasury of inflation protection securities should be lower than those on conventional Treasury securities. ${ }^{2}$

While it is generally presumed that nominal bonds bear an inflation risk premium, there has been very little research on modeling and estimating this premium, especially for U.S. dollar securities. Using data on the prices of existing nominal and indexed government debt, Foresi, Penati, and Pennacchi (1996) provide estimates of inflation risk premia, but only for the United Kingdom and Sweden where indexed bonds have already been issued. For the U.S., the only work of which we are aware is the recent paper by Campbell and Shiller (1996). They estimate bond risk premia in the context of

\footnotetext{
${ }^{1}$ Early in this century, Irving Fisher (1911) urged that "purchasing power bonds" be issued by the Federal government. Since then, a growing number of American economists, especially those in academia, have supported this idea.

${ }^{2}$ Federal Register 61(98), May 20, 1996, p.25165.
} 
a multi-factor Capital Asset Pricing Model, where risk factors are proxied using data on stock and bond market returns as well as changes in aggregate consumption.

If "saving" an inflation risk premium is the U.S. Treasury's primary motive for issuing indexed bonds, it would be worthwhile to understand the nature and size of this premium. ${ }^{3}$ Better knowledge of this premium could influence the proportion of total government debt that the Treasury might decide to index. Quantifying this inflation premium, as well as the risk premium from changes in real interest rates, is the primary goal of the present paper. In doing so, we will also provide estimates of the market prices of indexed bonds of various maturities.

It would appear difficult to estimate an inflation risk premium prior to the actual issuance of index bonds. The difficulty lies in disentangling the effects of real returns and inflation from only nominal bond prices. The approach taken in this paper is to use survey data on forecasts of inflation, in addition to nominal bond price data, to identify these separate effects. By proxying market expectations with survey forecasts, along with use of a powerful empirical technique, we are able to estimate a large number of parameters that are necessary for modeling nominal and indexed bond yield curves.

The analysis of this paper ignores some theoretical and practical considerations that could affect the value of indexed bonds. First, the market prices of real interest rate and inflation risk that we estimate from historical data are assumed to remain unchanged following the introduction of indexed bonds. This ignores possible general equilibrium effects on the value of nominal and indexed securities if and when indexed securities become widely available. If indexed bonds provide a new hedging vehicle which improves financial market completeness, market risk premia may change. Predicting the size and direction of this change would require a more detailed model of

\footnotetext{
${ }^{3}$ An arguement against treating the savings of an inflation risk premium as a benefit of indexed bonds is that the reduction in the Treasury's costs simply reflects a re-distribution of cashflows between taxpayers and bondholders. One could even argue that on a riskadjusted basis, the value of this redistribution is zero. Some counter-arguments exist, however. First, by issuing indexed bonds, the inflation risk absorbed by the government might be better allocated across all taxpayers, which could lead to more efficient risksharing between individual bondholders and taxpayers. Second, if issuing indexed bonds reduces the average cost of servicing debt, it could allow a reduction in other, moredistortionary revenue sources, such as income taxes.
} 
the economy than that presented in this paper. Second, our model ignores the effect of taxes on the relative values of nominal and indexed bonds. The value of indexed bonds will be influenced by whether the government chooses to tax their capital gains. ${ }^{4}$ If capital gains from index adjustments are taxed, then the real after-tax payments of indexed bonds will still be affected by inflation. Third, we neglect that, in practice, indexed bonds are not fully indexed, but have payments tied to a previous period's price index. This means that there is an indexation lag, that is, a period prior to the bond's payment date when indexed bonds lack inflation protection. The original U.S. Treasury proposal is for this period to be three months. Future versions of this paper will explicitly account for valuation effects of this indexation lag.

The plan of the paper is as follows. In Section 2 we present a two factor model for valuing nominal and indexed bonds. The two factors represent the levels of the real interest rate and expected inflation. Section 3 describes our data and empirical method. The model is cast in state space form and its parameters are estimated by maximum likelihood using a Kalman filter to recursively compute the likelihood function. The estimation results are presented in Section 4. There we also characterize nominal and indexed bond yield curves and provide a measure of the inflation risk premium. Section 5 concludes.

\section{Valuing Nominal and Indexed Bonds}

As in Constantinides (1992) and Turnbull and Milne (1991), we start from a nominal pricing kernel, $M$, a stochastic discount factor which regulates prices of contingent claims. The existence of such a pricing kernel is equivalent to the absence of pure arbitrage opportunities. ${ }^{5}$ The time $t$, nominal value, $V(t, \tau)$, of a contingent claim which entitles the owner to receive a possibly uncertain monetary cash flow at time $t+\tau, H(t+\tau)$, satisfies the pricing relation:

$$
V(t, \tau)=E_{t}\left[\frac{M(t+\tau)}{M(t)} H(t+\tau)\right]
$$

These quantities are nominal, that is, expressed in currency units. We define the general price level as $p(t)$. The relationship between nominal and

${ }^{4}$ Currently, the U.S. Treasury proposes to tax capital gains.

${ }^{5}$ Duffie (1996) provides a detailed derivation of this result. 
deflated (real) prices is summarized by the following:

$$
\begin{aligned}
v(t, \tau) & =E_{t}\left[\frac{M(t+\tau)}{M(t)} \frac{p(t+\tau)}{p(t)} \frac{H(t+\tau)}{p(t+\tau)}\right] \\
& =E_{t}\left[\frac{m(t+\tau)}{m(t)} h(t+\tau)\right]
\end{aligned}
$$

where the contingent claim's real price, $v(t, \tau) \equiv V(t, \tau) / p(t)$, and the real cash flow, $h(t+\tau) \equiv H(t+\tau) / p(t+\tau)$, satisfy a pricing equation analogous to that of the nominal quantities but using a real pricing kernel, $m(t) \equiv$ $M(t) p(t)$.

The general price level, $p(t)$, depends on an economy's transaction technology, as well as the monetary and fiscal policy of its government. In models with endogenous inflation, the covariance of inflation with consumption, and hence the inflation risk premium, can be positive or negative depending on investors' hedging attitudes towards inflation, which in turn are model specific. We choose not to derive the demand for and supply of money from first principles, with an eye to leaving the sign and size of the covariance of inflation with other sources of risk to be free to take on any feasible values.

\subsection{A Two-Factor Gaussian Model}

We write the law of motion for the price level $p(t)$ as

$$
\frac{d p}{p}=\pi d t+\sigma_{p} d z_{p}
$$

Our notation will denote a shock to variable $x$ by $d z_{x}$, a standard Wiener process, and denote the instantaneous correlation of the shocks to variables $x$ and $y$ by $\rho_{x y}$. Our term structure model is affected by real and nominal shocks. The real variable, which reflects variations in average productivity, is the real interest rate on a bond which pays an instantaneously riskless real return. This riskless real rate of return is denoted by $r(t)$. The nominal variable is $\pi(t)$, the expected instantaneous inflation rate. The joint process for $r$ and $\pi$ is

$$
\begin{aligned}
d r & =\left(a_{1}+b_{11} r+b_{12} \pi\right) d t+\sigma_{r} d z_{r} \\
d \pi & =\left(a_{2}+b_{21} r+b_{22} \pi\right) d t+\sigma_{\pi} d z_{\pi}
\end{aligned}
$$


or, more compactly, denoting the vector of state variables as $s(t) \equiv$ $\left[\begin{array}{l}r(t) \\ \pi(t)\end{array}\right]$

$$
d s=(a+B s) d t+\sigma d Z
$$

where $a \equiv\left[\begin{array}{l}a_{1} \\ a_{2}\end{array}\right], B \equiv\left[\begin{array}{ll}b_{11} & b_{12} \\ b_{21} & b_{22}\end{array}\right]$, and $\sigma \sigma^{\top} \equiv \sum=\left[\begin{array}{ll}\sigma_{r}^{2} & \rho_{r \pi} \sigma_{r} \sigma_{\pi} \\ \rho_{r \pi} \sigma_{r} \sigma_{\pi} & \sigma_{\pi}^{2}\end{array}\right]$. $a, B$, and $\Sigma$ are assumed to be constants. The above process for the state variables is a special case of the model in Langetieg (1980). Note that $r$ and $\pi$ can depend on each other, both instantaneously $\left(\rho_{r \pi} \neq 0\right)$ and in terms of their expected changes $\left(b_{12} \neq 0, b_{21} \neq 0\right)$. However, they do not depend on the price level, $p$, which is a requirement for the absence of money illusion. The above assumptions imply that $s(t)$ has a bivariate normal distribution with mean and covariance matrix

$$
\begin{aligned}
E_{t}[s(t+\tau)] & =\gamma(\tau)+\Psi(\tau) s(t) \\
\operatorname{Cov}_{t}\left[s(t+\tau)^{\top} s(t+\tau)\right] & \equiv Q(\tau)=\int_{0}^{\tau} \Psi(\omega) \sum \Psi(\omega)^{\top} d \omega
\end{aligned}
$$

where the $2 \times 2$ matrix $\Psi(\tau) \equiv e^{B \tau}$, and the $2 \times 1$ vector $\gamma(\tau) \equiv \Gamma(\tau) a$, where $\Gamma(\tau) \equiv \int_{0}^{\tau} \Psi(\omega) d \omega=B^{-1}(\Psi(\tau)-I)$. In addition, if the (real parts of the) eigenvalues of matrix $B$ are negative, then $s(t)$ has a stationary distribution with an unconditional expected (steady state) value of $\left[\begin{array}{c}r^{s s} \\ \pi^{s s}\end{array}\right]=-B^{-1} a$.

The nominal pricing kernel $M$ is given by

$$
-\frac{d M}{M}=i d t+\phi_{r} d z_{r}+\phi_{\pi} d z_{\pi}
$$

where $\phi_{r}$ and $\phi_{\pi}$ are constants which represent the market prices of risk from changes in real interest rates and inflation, respectively. It is straightforward to obtain this particular pricing kernel as the nominal marginal utility of a representative investor in a Cox, Ingersoll, and Ross (1985b)-type production economy (where the representative investor has a time-separable logarithmic utility function and the production technology has constant returns to scale) by suitably choosing the stochastic process governing the mean and volatility of production and inflation. ${ }^{6}$

\footnotetext{
${ }^{6}$ For example, see Constantinides (1991), Pennacchi (1991), and Sun (1991).
} 
It is well known that the expected rate of change of the nominal pricing kernel is equal to minus the instantaneous maturity nominal interest rate, $i(t)$, a property that equation (7) satisfies by construction. ${ }^{7}$ Analogously, the expected rate of change of the real pricing kernel is equal to minus the instantaneous real interest rate, $E_{t}[d m / m]=-r d t$. Since

$$
\begin{aligned}
i(t) & =-E_{t}\left[\frac{d M}{M}\right] \\
& =-E_{t}\left[\frac{d(m / p)}{m / p}\right] \\
& =-E_{t}\left[\frac{d m}{m}-\frac{d p}{p}-\frac{d m}{m} \frac{d p}{p}+\left(\frac{d p}{p}\right)^{2}\right] \\
i(t) & =r(t)+\pi(t)+\sigma_{m p}-\sigma_{p}^{2}
\end{aligned}
$$

the nominal interest rate, $i$, and the real interest rate, $r$, are related through an extended Fisher relation.

We can now compute the prices of pure discount (zero-coupon) bonds. Let $N(t, \tau)$ be the date $t$ nominal price of a nominal bond that pays $\$ 1$ with certainty at date $t+\tau$. Its value is given by equation (1) with $H(t+\tau)=$ 1. Because of assumed normality of the state variables, the expectation of pricing kernel can be computed as follows:

$$
\begin{aligned}
N(t, \tau) & =E_{t}[\exp \{\ln M(t+\tau)-\ln M(t)\}] \\
& =E_{t}\left[\exp \left\{\int_{t}^{t+\tau} d \ln M(t+\omega)\right\}\right] \\
& =E_{t}\left[\exp \left\{\begin{array}{c}
\left.-\int_{t}^{t+\tau}\left(i(\omega)+\frac{1}{2}\left[\phi_{r}^{2}+\phi_{\pi}^{2}+2 \rho_{r \pi} \sigma_{r} \sigma_{\pi}\right]\right) d \omega\right\} \\
-\int_{t}^{t+\tau}\left(\phi_{r} d z_{r}+\phi_{\pi} d z_{\pi}\right)
\end{array}\right]\right. \\
& =E_{t}\left[\exp \left\{A_{n}(t, \tau)\right\}\right] \\
& =\exp \left\{E_{t}\left[A_{n}(t, \tau)\right]+\frac{1}{2} \operatorname{Var}_{t}\left[A_{n}(t, \tau)\right]\right\} \\
& =J_{n}(\tau) \exp \left\{-w_{n} \Gamma(\tau) s(t)\right\}
\end{aligned}
$$

where the $1 \times 2$ vector $w_{n} \equiv\left[\begin{array}{ll}1 & 1\end{array}\right]$, and $J_{n}(\tau)$ is an expression, independent of $s(t)$, that given in the Appendix.

In a similar manner, we can value a zero-coupon indexed bond. Let $R(t, \tau)$ be the date $t$ real price of an indexed bond that pays $\$ p(t+\tau)$ at date

${ }^{7}$ See Theorem 1 in Cox, Ingersoll, and Ross (1985a). 
$t+\tau .^{8}$ Its value is given by equation (2) with $H(t+\tau)=p(t+\tau)$, that is, $h(t+\tau)=1$.

$$
\begin{aligned}
& R(t, \tau)=E_{t}[\exp \{\ln m(t+\tau)-\ln m(t)\}] \\
& =E_{t}\left[\exp \left\{\int_{t}^{t+\tau} d \ln m(t+\omega)\right\}\right] \\
& =E_{t}\left[\exp \left\{\begin{array}{c}
-\int_{t}^{t+\tau}\left(r(\omega)+\sigma_{m p}+\rho_{r \pi} \sigma_{r} \sigma_{\pi}+\frac{1}{2}\left[\phi_{r}^{2}+\phi_{\pi}^{2}-\sigma_{p}^{2}\right]\right) d \omega \\
-\int_{t}^{t+\tau}\left(\phi_{r} d z_{r}+\phi_{\pi} d z_{\pi}-\sigma_{p} d z_{p}\right)
\end{array}\right\}\right] \\
& =E_{t}\left[\exp \left\{A_{r}(t, \tau)\right\}\right] \\
& =\exp \left\{E_{t}\left[A_{r}(t, \tau)\right]+\frac{1}{2} \operatorname{Var}_{t}\left[A_{r}(t, \tau)\right]\right\} \\
& =J_{r}(\tau) \exp \left\{-w_{r} \Gamma(\tau) s(t)\right\}
\end{aligned}
$$

where the $1 \mathrm{x} 2$ vector $w_{r} \equiv\left[\begin{array}{ll}1 & 0\end{array}\right]$, and $J_{r}(\tau)$ is an expression, similar to $J_{n}(\tau)$ and also independent of $s(t)$, that is given in the Appendix.

We conclude this section by calculating another variable that will used in our empirical work. The rate of inflation between date $t$ and date $\tau$ that is expected at date $t$ equals

$$
\begin{aligned}
E_{t}[p(t+\tau) / p(t)] & =E_{t}[\exp \{\ln p(t+\tau)-\ln p(t)\}] \\
& =E_{t}\left[\exp \left\{\int_{t}^{t+\tau} d \ln p(t+\omega)\right\}\right] \\
& =E_{t}\left[\exp \left\{-\int_{t}^{t+\tau}\left(\pi(\omega)-\frac{1}{2} \sigma_{p}^{2}\right) d \omega+\int_{t}^{t+\tau} \sigma_{p} d z_{p}\right\}\right] \\
& =E_{t}\left[\exp \left\{A_{p}(t, \tau)\right\}\right] \\
& =\exp \left\{E_{t}\left[A_{p}(t, \tau)\right]+\frac{1}{2} \operatorname{Var}_{t}\left[A_{p}(t, \tau)\right]\right\} \\
& =J_{p}(\tau) \exp \left\{-w_{p} \Gamma(\tau) s(t)\right\}
\end{aligned}
$$

where the $1 \times 2$ vector $w_{p} \equiv-\left[\begin{array}{ll}0 & 1\end{array}\right]$, and $J_{p}(\tau)$ is an expression, independent of $s(t)$, that is also given in the Appendix.

${ }^{8}$ This assumes no indexation lag. Due to delays in the collection of price information, price indices are reported with a lag. Thus, for practical reasons, indexed bond payments can be linked only to a price index for a prior date. The difference between the payment date and the date of the price index equals the indexation lag. For U.K. government indexlinked gilts, the lag is eight months. The current U.S. Treasury proposal is for a three month lag. Future versions of the paper will value indexed bonds with an adjustment for this lag. 


\section{The Empirical Technique}

\subsection{Data}

Our bond price data consists of zero-coupon bond prices derived from nominal U.S. Treasury bill, note, and bond quotes using the smoothed Fama-Bliss method. See Bliss (1996) for a description of this fitting method and an analysis of its performance compared to other fitting methods. Bond prices were observed on the last trading day of each month over the period January 1970 to November 1995. At each observation date, we selected zero-coupon bond prices having the following eight maturities: $\frac{1}{4}, \frac{1}{2}, 1,2,3,5,7$, and 10 years. ${ }^{9}$ These bond prices would then correspond to the theoretical nominal zero-coupon bond prices given in equation (9) above.

In addition to this bond data, we used forecasts of the GDP deflator obtained from the Survey of Professional Forecasters. The American Statistical Association in conjunction with the National Bureau of Economic Research began conducting this quarterly survey in November of 1968, and it was taken over by the Federal Reserve Bank of Philadelphia in $1990 .{ }^{10}$ The survey asks professional forecasters for their prediction of the GDP deflator one, four, seven, ten, and 13 months into the future. The surveys are taken during the second month of each quarter and released at the end of that month or early in the third month of the quarter. As emphasized by Keane and Runkle (1990), this survey is limited to professional forecasters who are likely to have a strong incentive to utilize information in an efficient manner. If so, this data may match the expectations of inflation embedded in the market prices of bonds better than other survey data on inflation expectations.

We used the median forecast of the survey respondents for each of these five different horizons. In principle, if we divide this forecast by the GDP deflator corresponding to the time that the forecast is made, this measure would match our theoretical measure of $E_{t}[p(t+\tau) / p(t)]$ given by equation (11). However, because of reporting lags and subsequent revisions in GDP deflator data, it is not clear what measure of $p(t)$ the survey participants had in mind at the time of their forecasts. This problem can be overcome if we divide the four, seven, ten, and 13 month forecasts by the one month forecast.

\footnotetext{
${ }^{9}$ Because markets for longer maturity bonds tend to be thin, we limited the longest bond maturity to 10 years so as to minimize zero-coupon bond fitting errors.

${ }^{10}$ See Croushore $(1993,1996)$ for a detailed description of this survey data and an analysis of its forecasting performance.
} 
This would correspond to the theoretical expression $E_{t}\left[p(t+\tau) / p\left(t+\frac{1}{12}\right)\right]$ for $\tau=\frac{4}{12}, \frac{7}{12}, \frac{10}{12}$, and $\frac{13}{12}$ years. Using equation (11), this theoretical expression equals

$$
E_{t}\left[p(t+\tau) / p\left(t+\frac{1}{12}\right)\right]=\frac{J_{p}(\tau)}{J_{p}\left(\frac{1}{12}\right)} \exp \left\{-w_{p}\left[\Gamma(\tau)-\Gamma\left(\frac{1}{12}\right)\right] s(t)\right\}
$$

\subsection{Estimation Method}

Our model implies that nominal bond prices, given by equation (9), and inflation forecasts, given by equation (12), are both exponential functions of a linear combination of the state variables. Thus, the natural logs of bond prices and inflation forecasts will be linear in the state variables. Denote the date $t$ continuously-compounded yield on a nominal zero-coupon bond having $\tau$ periods until maturity as $y_{n}(t, \tau) \equiv-\frac{1}{\tau} \ln [N(t, \tau)]$. Similarly, denote the date $t$ forecast of the continuously-compounded, annualized inflation rate between date $t+\frac{1}{12}$ and date $t+\tau$ as $y_{p}(t, \tau)=\ln \left\{E_{t}\left[p(t+\tau) / p\left(t+\frac{1}{12}\right)\right]\right\} /(\tau-$ $\left.\frac{1}{12}\right)$. Because our observed zero-coupon bond prices are fitted from bid and ask quotes of coupon bonds, we assume that the observed $y_{n}(t, \tau)$ equals its theoretical value with measurement error:

$$
y_{n}(t, \tau)=j_{n}(\tau)+\alpha_{n}(\tau) s(t)+\varepsilon_{n}(t)
$$

where the scalar $j_{n} \equiv-\frac{1}{\tau} \ln \left[J_{n}(\tau)\right]$ and the $1 \mathrm{x} 2$ vector $\alpha_{n} \equiv \frac{1}{\tau} w_{n} \Gamma(\tau)$. Likewise, because our observed Survey of Professional Forecasters median forecast of inflation may deviate from the "true" market expectation of inflation, we assume that the observed $y_{p}(t, \tau)$ measures its theoretical value with error:

$$
y_{p}(t, \tau)=j_{p}(\tau)+\alpha_{p}(\tau) s(t)+\varepsilon_{p}(t)
$$

where the scalar $j_{p} \equiv \ln \left[J_{p}(\tau) / J_{p}\left(\frac{1}{12}\right)\right] /\left(\tau-\frac{1}{12}\right)$ and the $1 \mathrm{x} 2$ vector $\alpha_{p} \equiv$ $-w_{p}\left[\Gamma(\tau)-\Gamma\left(\frac{1}{12}\right)\right] /\left(\tau-\frac{1}{12}\right)$. Since we observe eight different maturity bond prices and four different horizon inflation forecasts at each date, we can "stack" eight versions of equation (13) and four versions of equation (14) to obtain a $12 x 1$ vector $y(t) \equiv\left[y_{n}\left(t, \tau_{1}\right) \cdots y_{n}\left(t, \tau_{8}\right) y_{p}\left(t, \tau_{1}\right) \cdots y_{p}\left(t, \tau_{4}\right)\right]^{\top}$ which equals

$$
y(t)=j+\alpha s(t)+\varepsilon(t)
$$

where $j$ is a $12 \mathrm{x} 1$ vector with elements equal to the $j_{n}(\tau)$ 's and $j_{p}(\tau)$ 's, $\alpha$ is a $12 \mathrm{x} 2$ vector with rows equal to the $\alpha_{n}(\tau)$ 's and $\alpha_{p}(\tau)$ 's, and $\varepsilon(t)$ is a $12 \mathrm{x} 1$ vector with elements equal to the $\varepsilon_{n}(t)$ 's and $\varepsilon_{p}(t)$ 's. 
Equations (5) and (15) comprise a state space system. The unobserved state variables, $r(t)$ and $\pi(t)$, follow the "state transition" equation (5), which is equivalent to a discrete-time bivariate AR(1) process. The "measuremen$\mathrm{t}$ " equation (15) equates observables $y(t)$ to a function of the state variables plus measurement noise, $\varepsilon(t)$. For estimation purposes, we assume that this measurement noise has a serially uncorrelated, mean-zero, multivariate normal distribution with a date $t$ covariance matrix that is diagonal with the first eight diagonal elements (corresponding to bond yields) equal to $\sigma_{\varepsilon n}^{2}$ and the last four diagonal elements (corresponding to expected inflation rates) equal to $\sigma_{\varepsilon p}^{2}$.

Given these distributional assumptions, maximum likelihood estimates of the model parameters can be obtained using a Kalman filter to recursively compute the likelihood function. This is a relatively powerful estimation procedure in that both cross-sectional (equation 15) and time-series (equation 5) model restrictions are imposed on the data. For details of this procedure, including how bond prices observed at a monthly frequency are optimally combined with inflation forecasts observed at a quarterly frequency, see Pennacchi (1991 p.66 and Appendix B). ${ }^{11}$

\section{Results}

\subsection{Term Structure Parameter Estimates}

The two-factor term structure model involves a large number of parameters (fifteen). For a few of these parameters, we have strong priors as to what values they should take because they can be directly estimated by other means. In particular, the variance of the price level, $\sigma_{p}^{2}$, and its covariance with the real pricing kernel, $\sigma_{m p}$, can be reasonably directly estimated. For a production economy with a representative, logarithmic utility investor, such as Cox, Ingersoll, and Ross (1985b), $\sigma_{m p}$ equals minus the covariance between the growth rate of the price level and the growth rate of real output (capital). Thus, using data on the GDP deflator and real GDP over the period 1959.Q1-1996.Q1, we estimated $\sigma_{p}=.02107$ and

\footnotetext{
${ }^{11}$ It should be noted that this paper imposes all theoretical cross-equation restrictions on the parameters of the measurement equations. In particular, the elements of the vector $j$ are not assumed to be an arbitrary constants, as in Pennacchi (1991), but are restricted to take values implied by the model. The Appendix details the theorectical values for the elements of $j$.
} 
$\sigma_{m p}=\rho_{m p} \sigma_{m} \sigma_{p}=.2866(.01426)(.02107)$ and fixed the parameters to these values prior to estimation. Recall from equation (8) that the nominal interest rate is given by $i(t)=r(t)+\pi(t)+\sigma_{m p}-\sigma_{p}^{2}$. Thus, our estimate of $\sigma_{m p}-\sigma_{p}^{2}=-.000358$ reduces the nominal interest rate by 3.5 basis points over the real rate plus the drift of the price level process.

The only other parameter that we restricted was the implied steady state instantaneous real interest rate, $r^{s s}$. As discussed in Merton (1980), precise estimation of expected real returns on financial assets generally requires a very long time series. Thus, we felt $r^{s s}$ could be constrained to a reasonable value, and we tried both $2 \%$ and $2.5 \%$.

The parameter estimates for the two cases, $r^{s s}=2 \%$ and $r^{s s}=2.5 \%$ are given in the first two columns of Table 1 . With the possible exception of the estimates for $\pi^{s s}$, there is little difference in the results for these two cases. The estimates of the elements of matrix $B$ are each statistically different from zero and, together, imply a stationary state variable process ${ }^{12}$. The relatively large size of the off-diagonal elements $\left(b_{12} \approx-.4, b_{21} \approx .8\right)$ indicate substantial serial dependence between the real rate and expected inflation. Regarding the elements of the covariance matrix, $\Sigma$, the estimated standard deviations, $\sigma_{r}$ and $\sigma_{\pi}$, suggest that changes in the expected instantaneous rate of inflation are more volatile than changes in the instantaneous real interest rate. Further, these changes are highly positively correlated $\left(\rho_{r \pi} \approx\right.$ $.82)$.

The market prices of risk from changes in real interest rates and inflation, $\phi_{r}$ and $\phi_{\pi}$, are approximately the same magnitude, $\approx-.23$. Their negative signs are what would be expected, as this implies that bond returns have positive real interest rate and inflation risk premia. However, these estimates are not statistically significant at the $5 \%$ level (though the real premium is borderline). The implied steady state inflation rates, $\pi^{s s}=2.75 \%, 3.0 \%$, may seem a bit low, but are still within a reasonable range. Lastly, the standard deviations of the measurement errors, $\sigma_{\text {bonds }}$ and $\sigma_{\text {forecast }}$, indicate that a typical error in the theoretical model's fit of the observed annualized bond yields is 16 basis points, while a typical error in the model fitting the annualized inflation forecasts is around 134 basis points. Thus, the model seems to be fitting the bond yields quite well, but the survey inflation forecasts rather poorly.

A measure of the mean-reversion of the state variables can be calculated

\footnotetext{
${ }^{12}$ That is, the real parts of the eignevalues of $\mathrm{B}$ are negative.
} 
from the point estimates for $B$ and $\Sigma$. Table 1 gives the half-lives for $r(t)$ and $\pi(t)$, that is, the expected time it takes for these state variables to return one half way back to their steady state levels following a deviation. Mean reversion for expected inflation (half-life $\approx 1.1$ years) is relatively stronger than that for the real interest rate (half-life $\approx 6.5$ years). Figures 1 and 2 illustrate the state variables mean-reverting tendencies by plotting their impulse response functions for a one-standard deviation shock from their steady state variables. ${ }^{13}$ Figure 1 is for the case in which a shock of $\sigma_{i}$ to state variable $i$ is coincident with a shock of $\rho_{i j} \sigma_{i} \sigma_{j}$ to state variable $j$, that is, it considers the likely correlation between shocks of the state variables. In contrast, Figure 2 considers independent shocks, so that an initial shock of $\sigma_{i}$ to state variable $i$ leads to no immediate change in state variable $j$. It is clear, especially from Figure 2, that the state variables are highly dependent upon each other. Note especially that an independent upward shock to inflation leads to a significant expected fall in the real interest rate. Hence, while the two state variables are instantaneously positively correlated, implying high volatility in short term rates, the expected future opposite movement in the state variables will lead to longer-term yields (being risk-adjusted averages of expected short rates) reacting in a much less volatile manner.

\subsection{Indexed Bonds and the Inflation Yield Premium}

Based on the parameter estimates for column two of Table 1, Figure 3 plots the term structure of interest rates for both nominal bonds and indexed bonds assuming that the initial state variables are equal to their steady state values. The nominal and indexed bond yields curves both are upward sloping and appear reasonable. An intuitive measure of the premium attributable to inflation risk is the spread between equivalent maturity nominal and indexed bond yields, less the expected inflation rate over the life of the bonds. Since both state variables start from their steady states levels, their expected values for any future horizon equal their current values, so that this premium can be calculated as

$$
y_{n}(t, \tau)-y_{r}(t, \tau)-\left(\pi^{s s}+\sigma_{m p}-\sigma_{p}^{2}\right)
$$

By construction, this inflation yield premium equals zero for the instantaneous maturity nominal and real yields. From Figure 3, we see that this

\footnotetext{
${ }^{13}$ All figures in the paper reflect parameter estimates for the case of $r^{s s}=2.5 \%$.
} 
yield premium is hump-shaped, reaching a maximum of 53.76 basis points at a maturity of 12.6 years. Thus, based on these model estimates, the size of the inflation risk premium, translated in terms of a yield premium, could be approximately one-half of one percent for longer-maturity bonds. This is one potential measure of the government savings attributable to issuing indexed bonds relative to nominal bonds.

These results should be treated with caution in that there are indications that the parameter estimates do not produce realistic yield curves for some values of the state variables sufficiently far from their steady states. For example, in Figure 4 we plot nominal and indexed bond yield curves for $r(t)=r^{s s}$, but $\pi(t)$ equal to 100,200 , and 300 basis points above its steady state level. Because $b_{12} \approx-.43$ is significantly negative, higher expected inflation leads to an expected decline in future real rates, which is indicated by the lowering of the indexed bond's yield curve. In addition, because $b_{21} \approx .81$ is significantly positive, this lowering of the real rate reduces the expected future values of $\pi$. The net effect is that an independent upward shock in the current inflation rate increases short term nominal interest rates, but may actually lower longer term nominal rates, producing rather extreme inverted nominal yield curves. A related anomaly is the highly positive value for the instantaneous correlation coefficient, $\rho_{r \pi} \approx .82$. The vast majority of previous studies of the relationship between real interest rates and expected inflation have found significant negative correlation between these variables. ${ }^{14}$ In one sense, our estimation results are consistent with the state variables moving in opposite directions, but the timing is different. As Figure 2 shows, an independent upward shock to inflation is expected to reduce future short term interest rates, so that long-term yields will not adjust one-for-one with an increase in $\pi$. This suggests that our parameter estimation procedure may be having difficulty identifying whether this opposite movement of the state variables is occurring instantaneously (which would occur if $\rho_{r \pi},<0$ ), or intertemporally (which would occur if one or more of the off-diagonal elements of $B$ were $<0)$.

\footnotetext{
${ }^{14}$ See Pennacchi (1991) and the references therein. Theoretically, one would expect negative correlation, at least when the nominal interest rate is low. Note that the real interest rate and expected inflation could, individually, become negative, but the nominal interest rate (equal to their sum plus $\sigma_{m p}-\sigma_{p}^{2}$ ) cannot, else currency would dominate bonds. If the nominal rate is positive, but near zero, a fall in one state variable (e.g., the real interest rate) would need to be offset by a rise in the other (e.g., expected inflation). See Black (1995) for more discussion.
} 


\subsection{Results for a Restricted Model}

In an attempt to remedy the yield curve peculiarities of the previous section, we re-estimated the model under the restriction $b_{12}=b_{21}=0$, that is, that $B$ is a diagonal matrix. This restriction removes the intertemporal, but not the instantaneous, dependence between the state variables. The results for the case of $r^{s s}=2.0 \%$ and $r^{s s}=2.5 \%$ are given in columns three and four of Table 1. The estimates of $b_{11}$ and $b_{22}$ are both negative and statistically significant, though $b_{11}$ is quite small and implies very weak mean-reversion for the real interest rate. Both $\sigma_{r}$ and $\sigma_{\pi}$ are slightly larger than in the unrestricted case and, most interestingly, $\rho_{r \pi}$ switches from being significantly positive to being significantly negative. ${ }^{15}$ As mentioned earlier, this significant negative correlation between real rates and expected inflation is consistent with the bulk of previous empirical work. The restriction on $B$ also has sizable effects on the estimates of the risk premia. $\phi_{r}$ declines, but $\phi_{\pi}$ rises and both are now statistically significant. There is not much difference in the estimated steady state inflation rate, $\pi^{s s}$ : it falls slightly to $2.9 \%$. Importantly, the restricted likelihood function does not decline very much: a likelihood ratio test cannot reject the diagonality of $B$ at reasonable confidence levels.

Figure 5 illustrates the implications of these restricted estimates for the nominal and indexed bond yield curves and the inflation yield premium. The indexed yield curve is flatter than the previous case, while the nominal yield curve is reasonably upward sloping. This results in an inflation yield premium that is significantly larger than that of the unrestricted case. Here, the inflation yield premium for a 10 year zero-coupon bond is 219 basis points versus 53 basis points for the unrestricted case. Also, while not displayed here, the restricted case's indexed and nominal yield curves do not exhibit extreme inverted shapes when the state variables deviate from their steady states. In this sense, these restricted yield curves have more realistic characteristics than the unrestricted ones.

Having estimated the parameters for what appears to be a more realistic model, we can now compute the best estimates of the levels of the (unobserved) state variables over the sample period, a process called smoothing. ${ }^{16}$

\footnotetext{
${ }^{15}$ While the results are not presented here, we also estimated the model under the single restriction that either $b_{12}$ or $b_{21}$ equals zero. However, under these assumptions, the correlation coefficient remained positive and statistically significant: $\rho_{r \pi} \approx .16$ when only $b_{12}=0 ;$ and $\rho_{r \pi} \approx .36$ when only $b_{21}=0$.

${ }^{16}$ For a description of smoothing, see Harvey (1981).
} 
The results of this are illustrated in Figure 6, which plots the estimated times series for the real interest rate, expected inflation, and, for the sake of comparison, the Fama-Bliss three-month bond yield. Notably, there are periods during the 1970's and 1990's when the instantaneous real interest rate became negative. The negative correlation of real rates and expected inflation is also apparent from this figure. Figure 7 plots the same estimated time series of expected inflation, but compares it to the actual level of inflation given by the actual quarterly change in the GDP deflator. There was an extended period of time in the late 1970's when actual inflation appeared to be systematically higher than investors' expectations. Similarly, actual inflation was frequently lower than what was expected during the late 1980's and early 1990's. However, we caution against concluding that these episodes indicate irrational expectations. Investors may require a significant accumulation of evidence before a change in monetary policy is viewed to be credible.

In summary, this restricted model produces sensible term structures of real and nominal interest rates and implies dynamics for real interest rates and inflation that are consistent with prior research. Given that its restrictions cannot be statistically rejected, it should be preferred to its unrestricted counterpart.

\section{Conclusion}

This paper provides a framework for valuing bonds having payments indexed to a price level. Using survey forecasts of inflation as a proxy for market expectations, we were able to identify the separate influences of real returns and inflation embedded in nominal bond prices. In addition, the paper's maximum likelihood technique, which imposes both cross-sectional and timeseries restrictions on the sample of observations, allowed us to calculate a large number of model parameters relatively accurately. Based on these parameter estimates, we could construct nominal and indexed bond yield curves and calculate investors' required premia for risk from changes in both real interest rates and inflation.

The term structures implied by the unrestricted parameter estimates appeared to display excessive curvature when inflation was significantly above its steady state level. By restricting the state variable process in a way that reduced intertemporal dependence, we obtained nominal and indexed bond yield curves that appeared more realistic. Importantly, this state vari- 
able process restriction could not be statistically rejected by the data, which leads us to conclude that it represents an improvement over the unrestricted version. Based on our results for this restricted model, we found that the size of an inflation yield premium to be approximately 220 basis points for a 10 year zero-coupon bond. Subject to the modeling and estimation caveats previously discussed, this suggests that the potential government budgetary "savings" from issuing indexed bonds are substantial. 


\section{Appendix}

This Appendix gives the values for $J_{n}(\tau), J_{r}(\tau)$, and $J_{p}(\tau)$ presented in section 2.1 of the text. Their values can be derived from the results of Langetieg (1980). For $i=n, r$, or $p, J_{i}(\tau)$ is given by the following formula:

$$
\begin{aligned}
\ln \left[J_{i}\right]= & -\tau\left(u_{i}-w_{i} B^{-1} a\right)-w_{i} \Gamma(\tau) B^{-1} a \\
& +d_{i} w_{i} B^{-1}(\Gamma(\tau)-I \cdot \tau) \Phi+\frac{1}{2} w_{i} \Gamma(\tau)-\Gamma(\tau)^{\top} w_{i} \\
& -\frac{1}{2} w_{i}\left(B^{-1} \Gamma(\tau)-+-\Gamma(\tau)^{\top}\left(B^{-1}\right)^{\top}\right) w_{i}^{\top} \\
& +\frac{1}{2} w_{i} B^{-1} \Sigma\left(B^{-1}\right)^{\top} w_{i}^{\top} \tau
\end{aligned}
$$

where $\Phi \equiv\left[\begin{array}{c}\sigma_{r} \phi_{r} \\ \sigma_{\pi} \phi_{\pi}\end{array}\right], u_{n}=\sigma_{m p}-\sigma_{p}^{2}, u_{r}=0, u_{p}=-\frac{1}{2} \sigma_{p}^{2}, d_{n}=d_{r}=1$, and $d_{p}=0$. The $2 \mathrm{x} 2$ matrix - is defined as follows. Let $\lambda_{i}, i=1,2$, be the eigenvalues of $B$, and let $C$ be a $2 \times 2$ matrix whose columns are the corresponding eigenvectors. Define $\Sigma^{*} \equiv C^{-1} \Sigma\left(C^{-1}\right)^{\top}$, which is a $2 \mathrm{x} 2$ matrix with elements $\sigma_{i j}^{*}$ and then define $\Sigma^{* *}$ as a $2 \mathrm{x} 2$ matrix with elements equal to $\sigma_{i j}^{*} /\left(\lambda_{i}+\lambda_{j}\right)$. Then - $\equiv C \Sigma^{* *} C^{\top}$. Note that once - is calculated, the covariance matrix of the state variable process, $Q(\tau)$, given in equation (6) can be calculated: $Q(\tau)=\Psi(\tau)-\Psi(\tau)^{\top}-$ - . 


\section{References}

Black, F., 1995, "Interest Rates as Options," Journal of Finance 50, 1371-1376.

Bliss, R., 1996, "Testing Term Structure Estimation Methods," Working Paper 96-12, Federal Reserve Bank of Atlanta.

Campbell, J., and R. Shiller, 1996, "A Scorecard for Indexed Government Debt," Working Paper 5587, National Bureau of Economic Research (May).

Constantinides, G., 1992, "A Theory of the Nominal Term Structure of Interest Rates," Review of Financial Studies 5, 531-552.

Cox, J., J. Ingersoll, and S. Ross, 1985a, "An Intertemporal General Equilibrium Model of Asset Prices," Econometrica 53, 363-384.

Cox, J., J. Ingersoll, and S. Ross, 1985b, "A Theory of the Term Structure of Interest Rates," Econometrica 53, 385-407.

Croushore, D., 1996, "Inflation Forecasts: How Good Are They?," Business Review Federal Reserve Bank of Philadelphia (May-June), $15-25$.

Croushore, D., 1993, "Introducing: The Survey of Professional Forecasters," Business Review Federal Reserve Bank of Philadelphia (November-December), 3-15.

Duffie, D., 1996, Dynamic Asset Pricing Theory, 2nd ed., Princeton University Press.

Fisher, I, 1911, The Purchasing Power of Money, Macmillan.

Foresi, S., A. Penati, and G. Pennacchi, 1996, "Reducing the Cost of Government Debt: The Italian Experience and the Role of Indexed Bonds," Swedish Economic Policy Review 3, 203-232.

Harvey, A.C., 1981, " Time Series Models, Wiley, New York. 
Keane, M. and D. Runkle, 1990, "Testing the Rationality of Price Forecasts: New Evidence from Panel Data," American Economic Review $80,714-35$.

Langetieg, T., 1980, "A Multivariate Model of the Term Structure," Journal of Finance 35, 71-97.

Merton, R.C., 1980, "On Estimating the Expected Return on the Market: An Exploratory Investigation," Journal of Financial Economics 8, 323-61.

Pennacchi, G., 1991, "Identifying the Dynamics of Real Interest Rates and Inflation: Evidence Using Survey Data," Review of Financial Studies 4, 53-86.

Sun, T.S., 1992, "Real and Nominal Interest Rates: A Discrete-Time Model and Its Continuous-Time Limit," Review of Financial Studies $5,581-612$.

Turnbull, S. and F. Milne, 1991, "A Simple Approach to Interest-Rate Option Pricing," Review of Financial Studies 4, 87-120. 
Table 1

U.S. Real Interest Rate - Expected Inflation Process Estimates

$$
\left(\begin{array}{c}
d r \\
d \pi
\end{array}\right)=\left[\left(\begin{array}{l}
a_{1} \\
a_{2}
\end{array}\right)+\left(\begin{array}{ll}
b_{11} & b_{12} \\
b_{21} & b_{22}
\end{array}\right)\left(\begin{array}{c}
r(t) \\
\pi(t)
\end{array}\right)\right] d t+\left(\begin{array}{c}
\sigma_{r} d z_{r} \\
\sigma_{\pi} d z_{\pi}
\end{array}\right)
$$

(standard errors in parentheses)

\begin{tabular}{|c|c|c|c|c|}
\hline \multirow[b]{2}{*}{ Parameter } & \multirow[b]{2}{*}{$\underline{s s}^{s}=2.0 \%$} & \multirow[b]{2}{*}{$\underline{s s}=2.5 \%$} & \multicolumn{2}{|c|}{$b_{12}=b_{21}=0$} \\
\hline & & & $\underline{r^{s}}=2.0 \%$ & $\underline{r}^{s s}=2.5 \%$ \\
\hline$b_{11}$ & $\begin{array}{c}0.2938 \\
(0.0820)\end{array}$ & $\begin{array}{c}0.2881 \\
(0.0822)\end{array}$ & $\begin{array}{l}-0.0344 \\
(0.0015)\end{array}$ & $\begin{array}{l}-0.0344 \\
(0.0015)\end{array}$ \\
\hline$b_{12}$ & $\begin{array}{l}-0.4193 \\
(0.0971)\end{array}$ & $\begin{array}{l}-0.4273 \\
(0.1000)\end{array}$ & 0 & 0 \\
\hline$b_{21}$ & $\begin{array}{c}0.8420 \\
(0.1106)\end{array}$ & $\begin{array}{c}0.8080 \\
(0.1099)\end{array}$ & 0 & 0 \\
\hline$b_{22}$ & $\begin{array}{l}-1.0930 \\
(0.0828)\end{array}$ & $\begin{array}{l}-1.0875 \\
(0.0831)\end{array}$ & $\begin{array}{c}-0.7732 \\
(.0083)\end{array}$ & $\begin{array}{l}-0.7733 \\
(0.0083)\end{array}$ \\
\hline$\sigma_{r}$ & $\begin{array}{c}0.0100 \\
(0.0006)\end{array}$ & $\begin{array}{c}0.0102 \\
(0.0006)\end{array}$ & $\begin{array}{c}0.0151 \\
(0.0005)\end{array}$ & $\begin{array}{c}0.0151 \\
(0.0005)\end{array}$ \\
\hline$\sigma_{\pi}$ & $\begin{array}{c}0.0169 \\
(0.0007)\end{array}$ & $\begin{array}{c}0.0168 \\
(0.0007)\end{array}$ & $\begin{array}{c}0.0229 \\
(0.0008)\end{array}$ & $\begin{array}{c}0.0229 \\
(0.0008)\end{array}$ \\
\hline$\rho_{\mathrm{r} \pi}$ & $\begin{array}{c}0.8235 \\
(0.2414)\end{array}$ & $\begin{array}{c}0.8213 \\
(0.2439)\end{array}$ & $\begin{array}{l}-0.1260 \\
(0.0464)\end{array}$ & $\begin{array}{l}-0.1263 \\
(0.0464)\end{array}$ \\
\hline$\phi_{\mathrm{r}}$ & $\begin{array}{l}-0.2553 \\
(0.1344)\end{array}$ & $\begin{array}{l}-0.2339 \\
(0.1347)\end{array}$ & $\begin{array}{l}-0.1011 \\
(0.0078)\end{array}$ & $\begin{array}{l}-0.0899 \\
(0.0077)\end{array}$ \\
\hline$\phi_{\pi}$ & $\begin{array}{l}-0.2387 \\
(0.2160)\end{array}$ & $\begin{array}{l}-0.2237 \\
(0.2165)\end{array}$ & $\begin{array}{l}-0.8587 \\
(0.2191)\end{array}$ & $\begin{array}{l}-0.8538 \\
(0.2175)\end{array}$ \\
\hline$\pi^{\mathrm{ss}}$ & $\begin{array}{c}0.0276 \\
(0.0011)\end{array}$ & $\begin{array}{c}0.0301 \\
(0.0011)\end{array}$ & $\begin{array}{c}0.0287 \\
(0.0035)\end{array}$ & $\begin{array}{c}0.0288 \\
(0.0035)\end{array}$ \\
\hline$\sigma_{\text {bonds }}$ & $\begin{array}{c}0.0016 \\
\left(1.3 \times 10^{-5}\right)\end{array}$ & $\begin{array}{c}0.0016 \\
\left(1.3 \times 10^{-5}\right)\end{array}$ & $\begin{array}{l}0.0016 \\
\left(1.3 \times 10^{-5}\right)\end{array}$ & $\begin{array}{c}0.0016 \\
\left(1.3 \times 10^{-5}\right)\end{array}$ \\
\hline$\sigma_{\text {forecast }}$ & $\begin{array}{c}0.0133 \\
(0.0003)\end{array}$ & $\begin{array}{c}0.0135 \\
(0.0003)\end{array}$ & $\begin{array}{c}0.0170 \\
(0.0004)\end{array}$ & $\begin{array}{c}0.0170 \\
(0.0004)\end{array}$ \\
\hline $\begin{array}{l}\text { Halflife } \mathrm{r} \\
\text { Halflife } \pi\end{array}$ & 6.54 years & 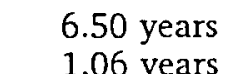 & $\begin{array}{c}20.17 \text { years } \\
0.90 \text { years }\end{array}$ & $\begin{array}{c}20.17 \text { years } \\
0.90 \text { years }\end{array}$ \\
\hline Ln likelihood & 44.5038 & 44.4865 & 44.1516 & 44.1505 \\
\hline
\end{tabular}

Note: Maximum likelihood estimates are obtained using monthly .25, .5, 1, 2, 3, 5,7 , and 10 year smoothed Fama-Bliss zero coupon bonds and quarterly Survey of Professional Forecasters median predictions of the GDP deflator for 4, 7, 10, and 13 month horizons. Sample period is January 1970 to November 1995. $\rho_{\mathrm{r} \pi} \mathrm{dt}=\mathrm{dz} \mathrm{r}_{\mathrm{r}} \mathrm{dz}{ }_{\pi} \cdot \phi_{\mathrm{r}}$ and $\phi_{\pi^{*}}$ denote the real interest rate and inflation risk premiums, respectively. $r^{\mathrm{ss}}$ and $\pi^{\mathrm{ss}}$ are the respective steady state levels of the real interest rate and inflation. 
Figure 1

Expected Paths of Real Interest Rate and Inflation

After One Standard Deviation Correlated Jump in Real Rate

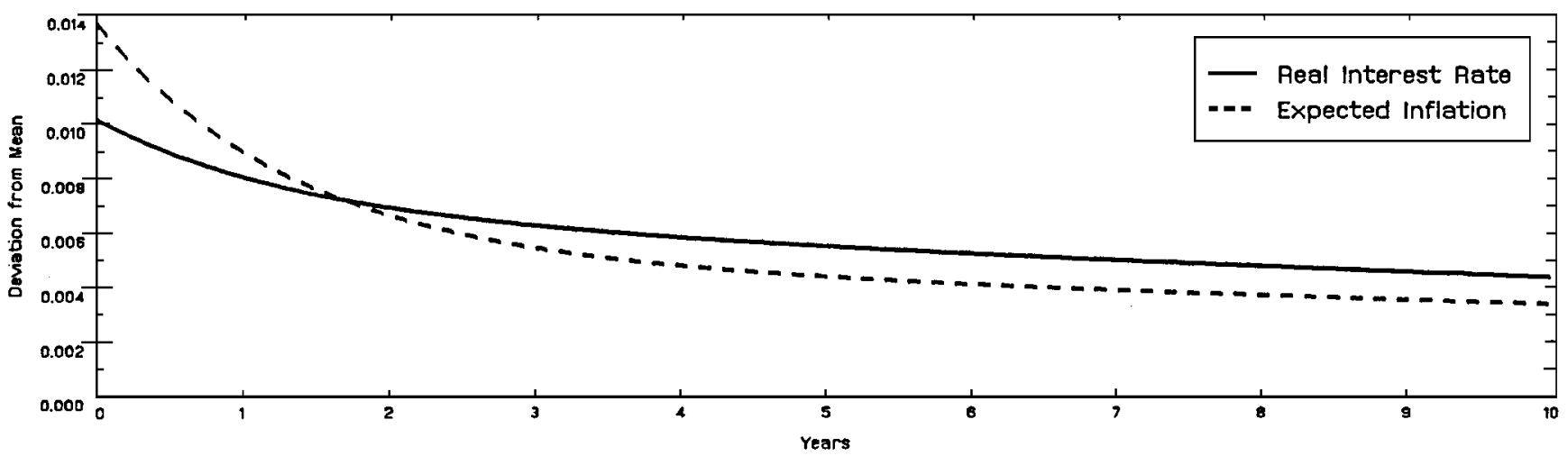

Expected Paths of Real Interest Rate and Inflation

After One Standard Deviation Correlated Jump in Expected Inflation

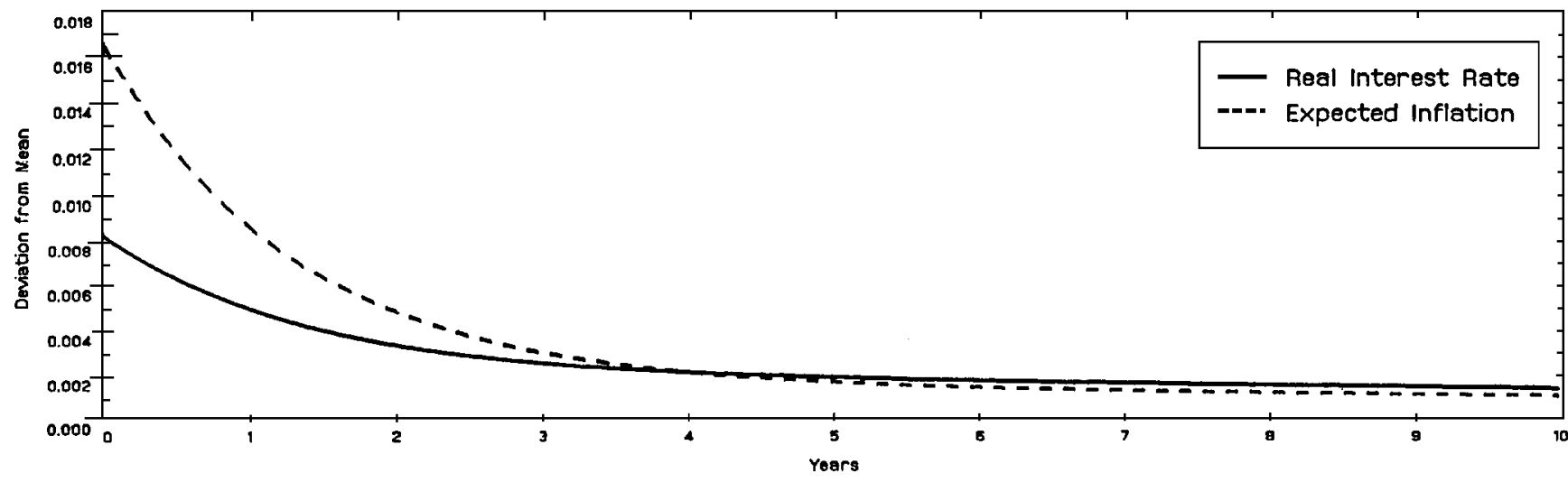


Figure 2

Expected Paths of Real Interest Rate and Inflation

After One Standard Deviation Independent Jump in Real Rate

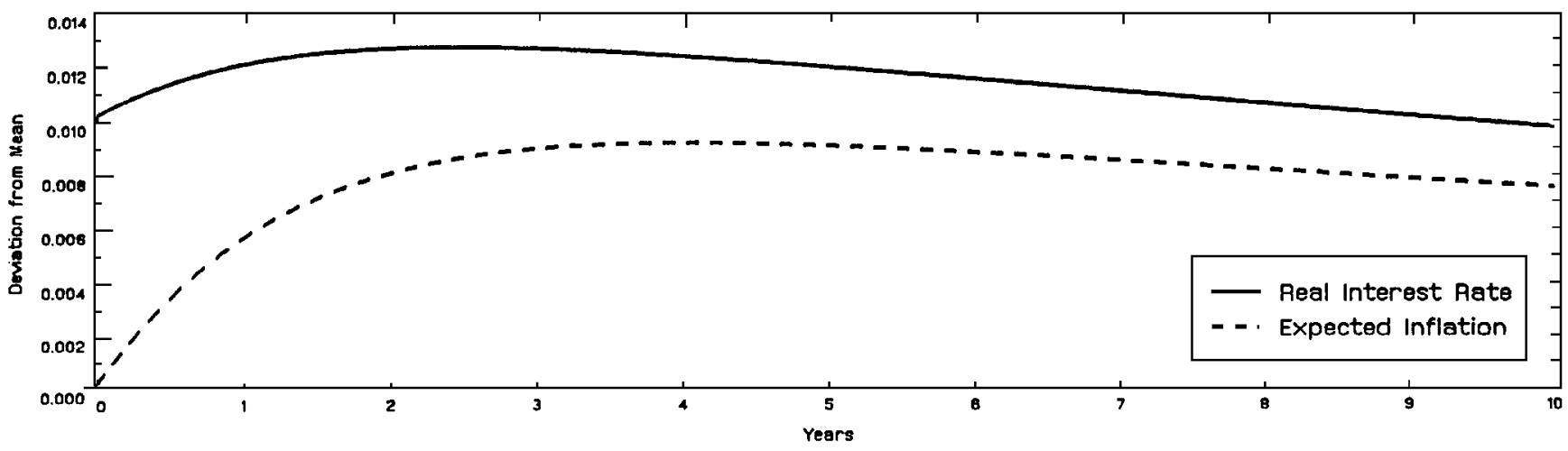

Expected Paths of Real Interest Rate and Inflation

After One Standard Deviation Independent Jump in Expected Inflation

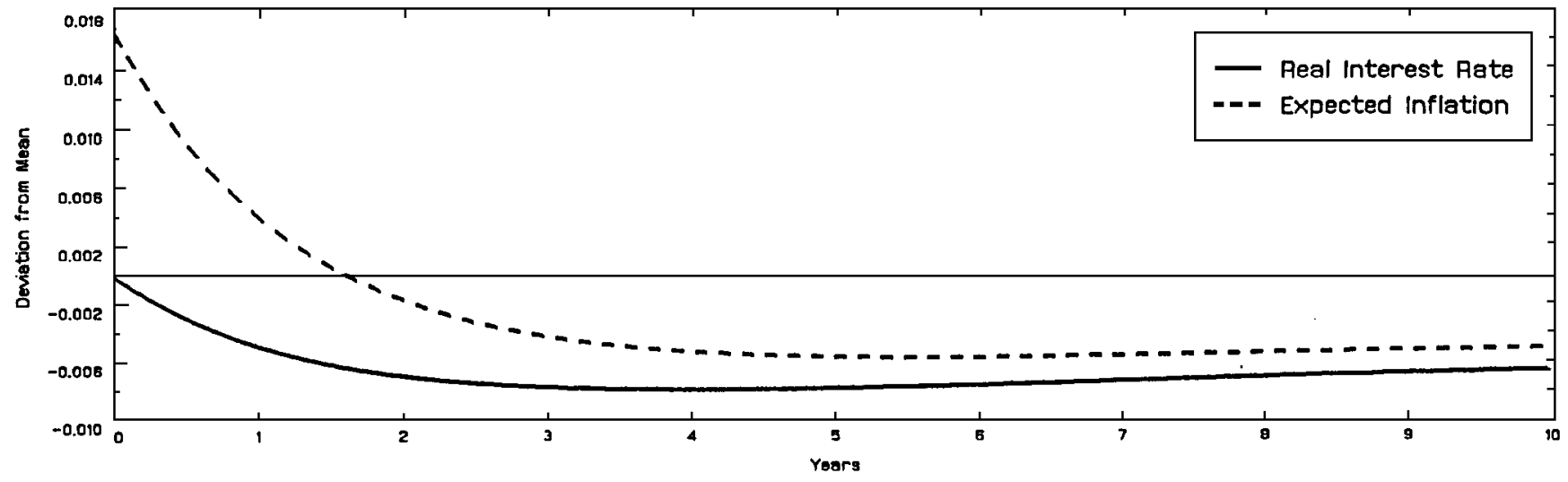


Figure 3

Nominal and Indexed Bond Term Structures [Initial State Variables Equal Steady States]

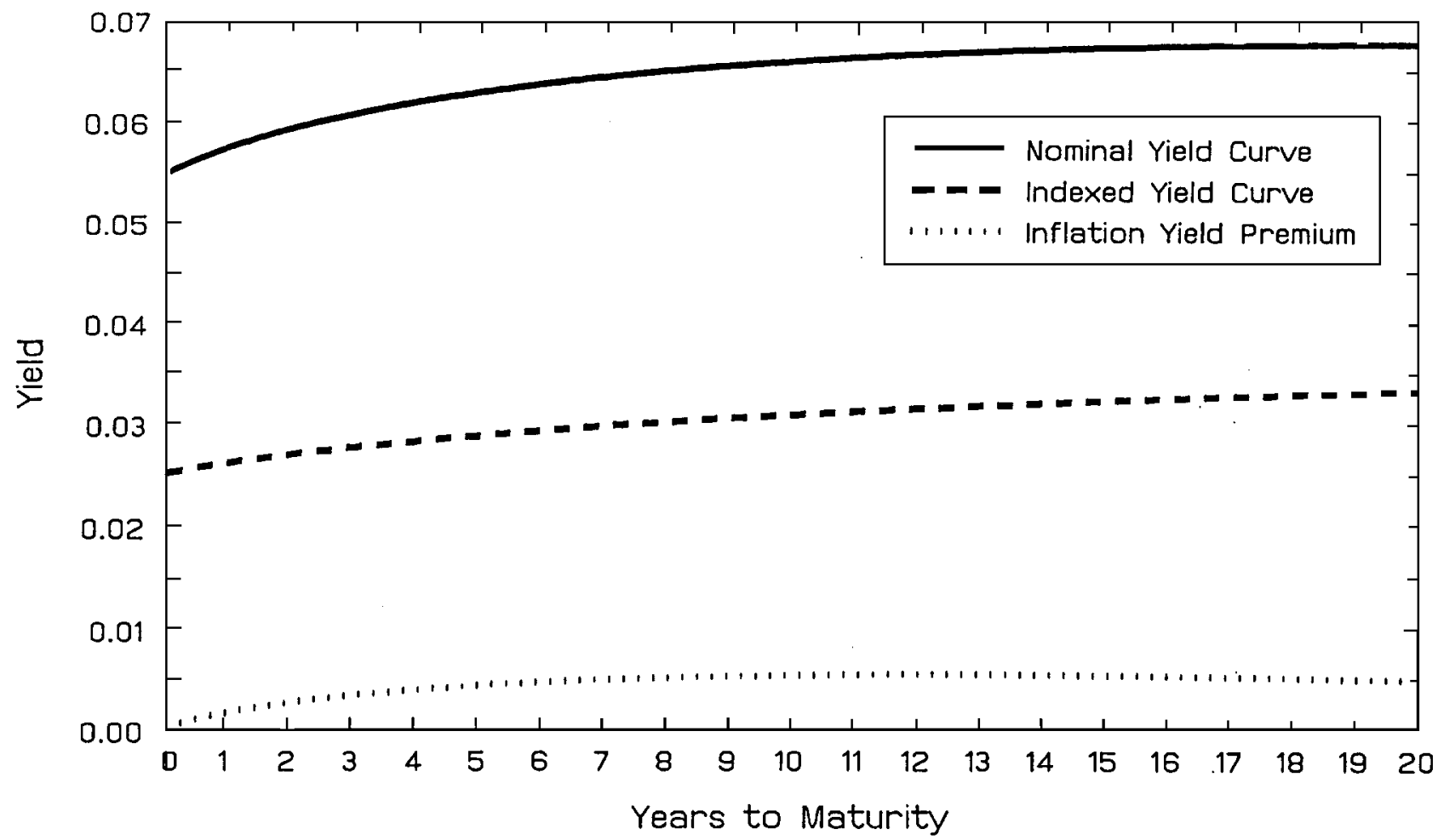


Figure 4

Nominal and Indexed Bond Term Structures [Initial Inflation Above Steady State]

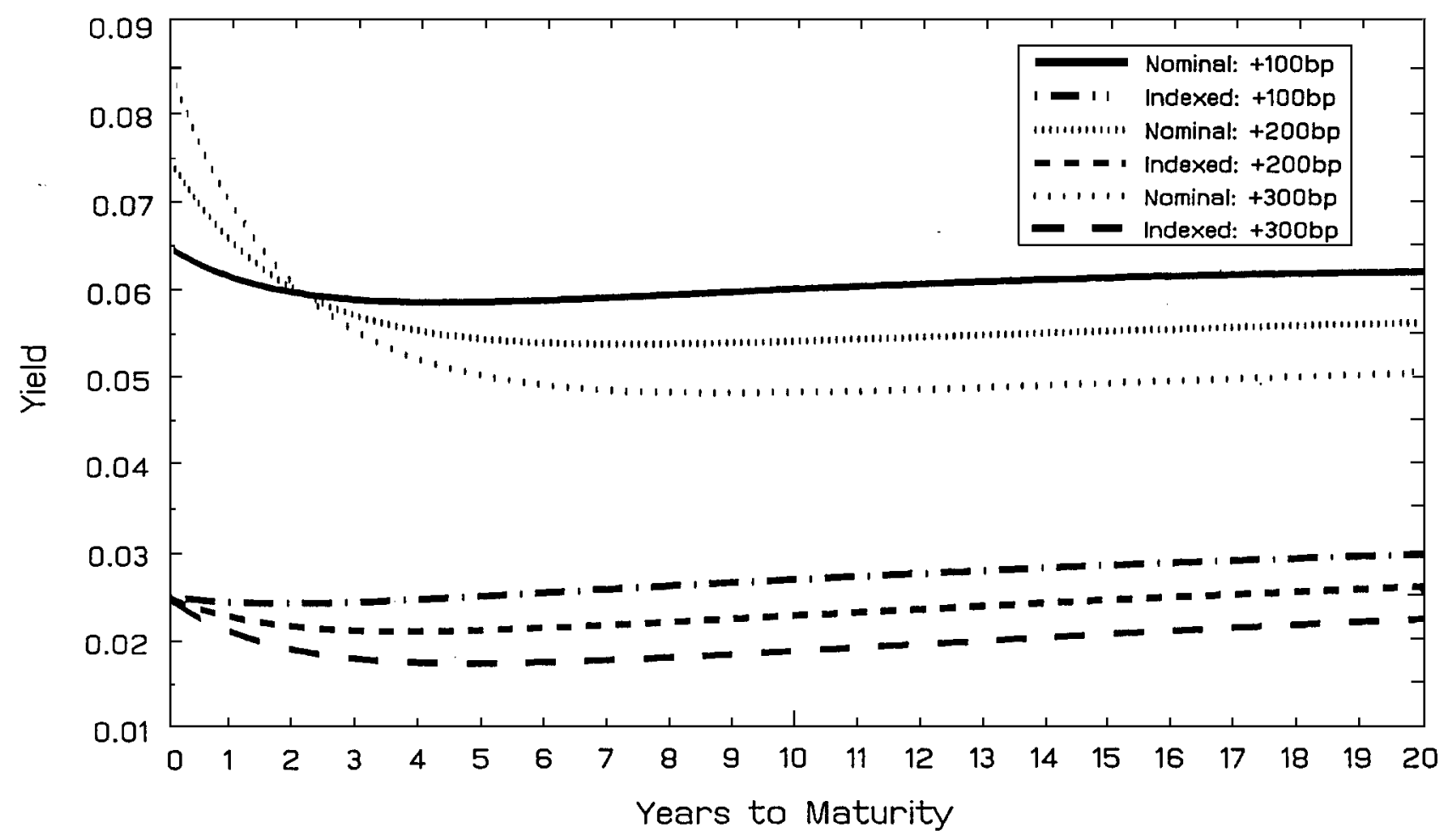


Figure 5

Nominal and Indexed Bond Term Structures

$[\mathrm{B} 12=\mathrm{B} 21=0$, Initial State Variables Equal Steady States $]$

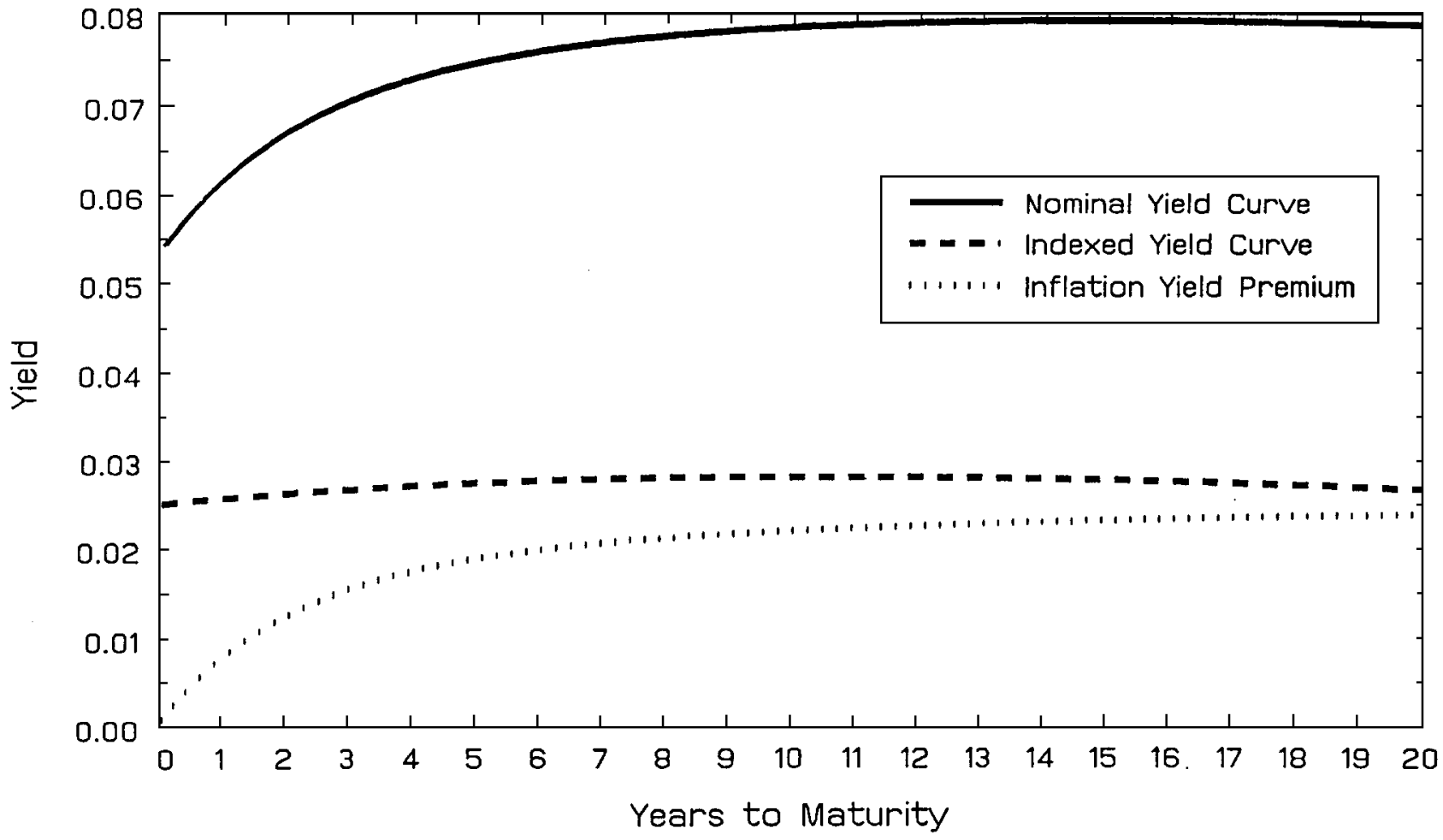


Figure 6

Real Rate, Expected Inflation, and Three-Month Bond Yield

$\mathrm{B} 12=\mathrm{B} 21=0$

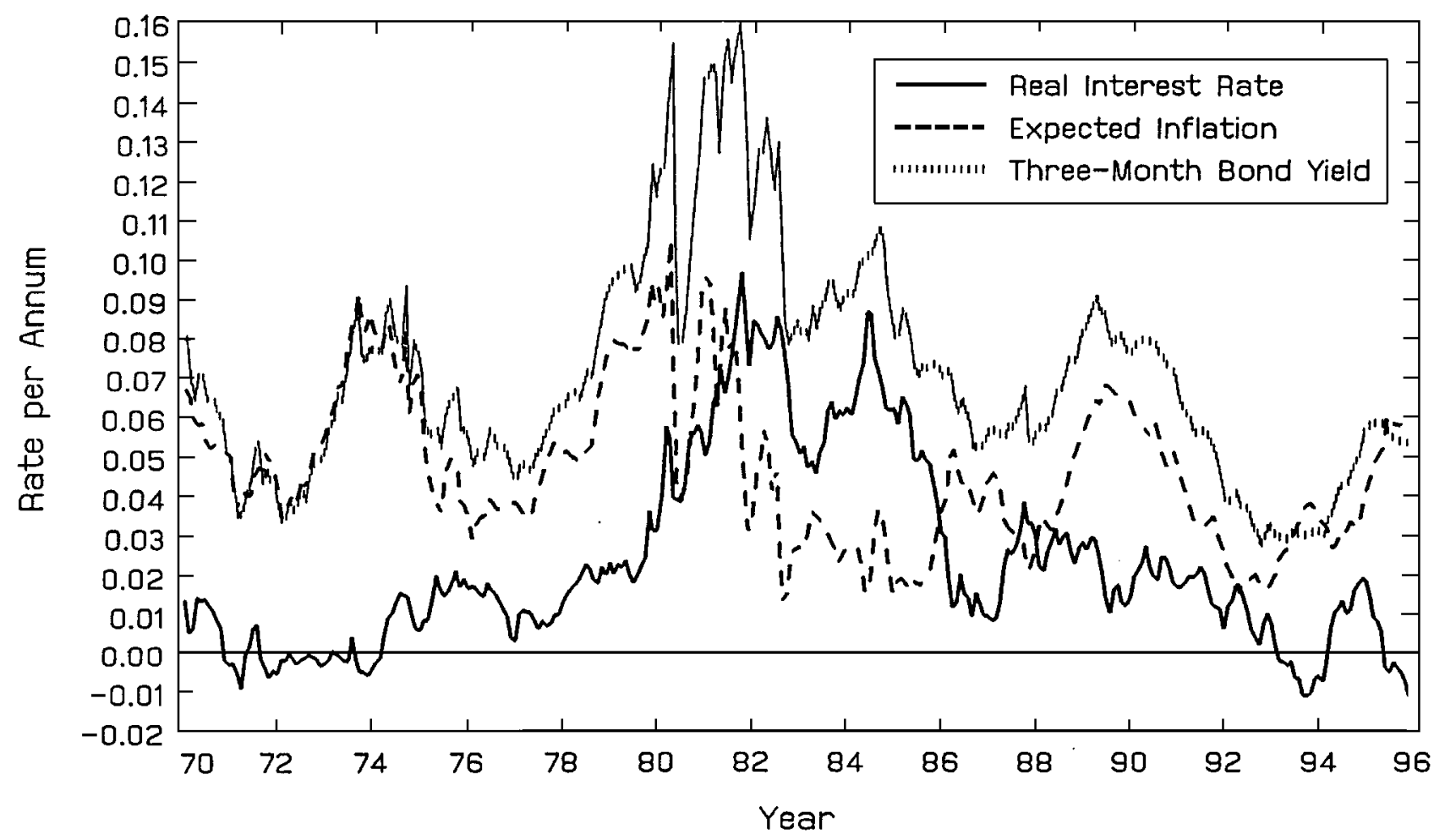


Figure 7

U.S. Expected and Actual Inflation

$\mathrm{B} 12=\mathrm{B} 21=0, \%$ Changes in Quarterly GDP Deflator

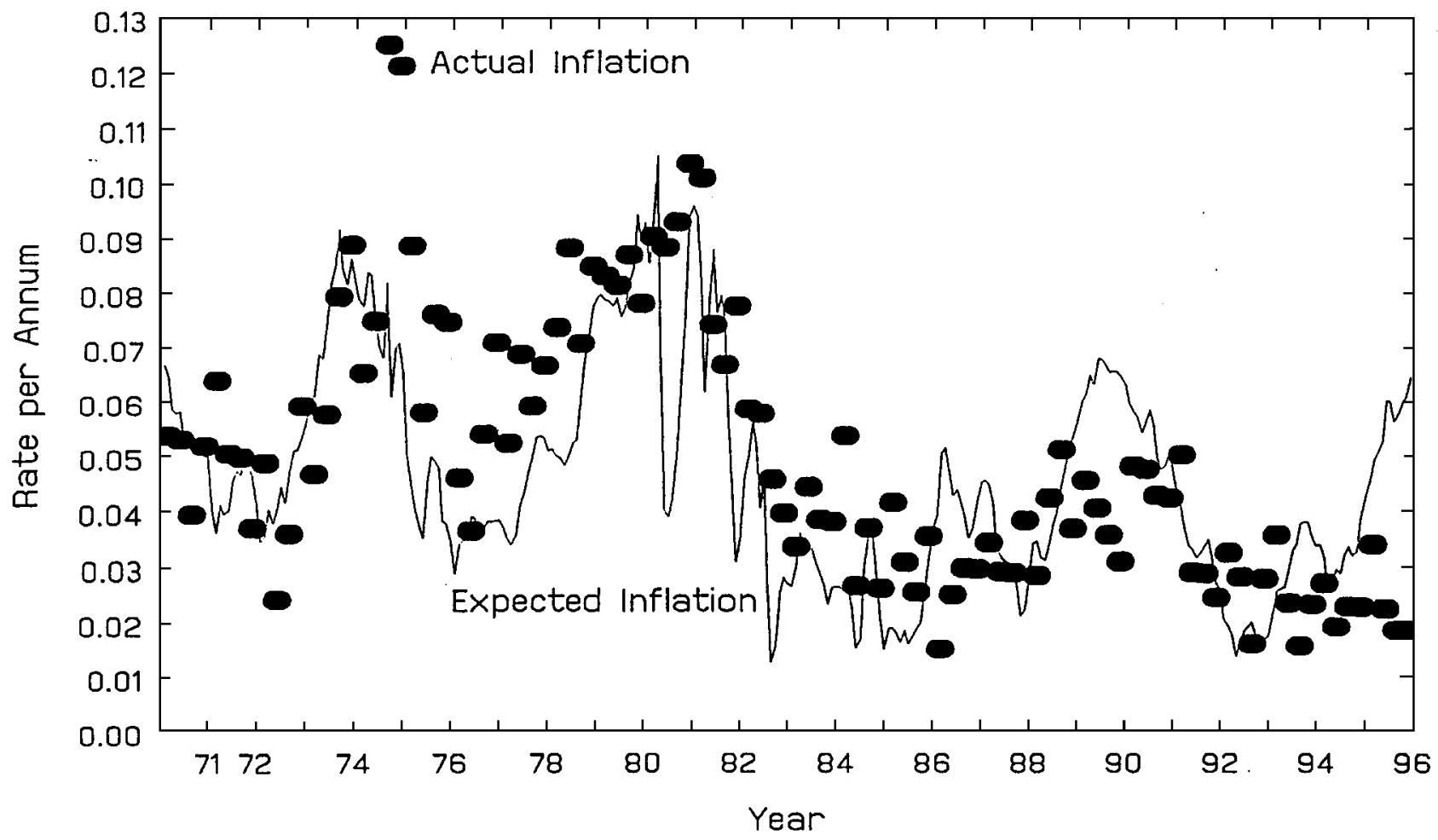

